\title{
Effect of GABAergic inhibition on odorant concentration coding in mushroom body intrinsic neurons of the honeybee
}

\author{
Anja Froese $\cdot$ Paul Szyszka $\cdot$ Randolf Menzel
}

\begin{abstract}
Kenyon cells, the intrinsic neurons of the insect mushroom body, have the intriguing property of responding in a sparse way to odorants. Sparse neuronal codes are often invariant to changes in stimulus intensity and duration, and sparse coding often depends on global inhibition. We tested if this is the case for honeybees' Kenyon cells, too, and used in vivo $\mathrm{Ca}^{2+}$ imaging to record their responses to different odorant concentrations. Kenyon cells responded not only to the onset of odorant stimuli (ON responses), but also to their termination (OFF responses). Both, ON and OFF responses increased with increasing odorant concentration. ON responses were phasic and invariant to the duration of odorant stimuli, while $\mathrm{OFF}$ responses increased with increasing odorant duration. Pharmacological blocking of GABA receptors in the brain revealed that ionotropic $\mathrm{GABA}_{\mathrm{A}}$ and metabotropic $\mathrm{GABA}_{\mathrm{B}}$ receptors attenuate Kenyon cells' ON responses without changing their OFF responses. Ionotropic $\mathrm{GABA}_{\mathrm{A}}$ receptors attenuated Kenyon cell $\mathrm{ON}$ responses more strongly than metabotropic $\mathrm{GABA}_{\mathrm{B}}$ receptors. However, the response dynamic, temporal resolution and paired-pulse depression did not depend on $\mathrm{GABA}_{\mathrm{A}}$ transmission. These data are discussed in the context of mechanisms leading to sparse coding in Kenyon cells.
\end{abstract}

Keywords Kenyon cells $\cdot \mathrm{Ca}^{2+}$ imaging $\cdot$ Olfactory coding - GABA receptors - OFF responses

\author{
A. Froese · R. Menzel $(\bowtie)$ \\ Institut für Neurobiologie, Freie Universität Berlin, \\ Königin Luise Str. 28/30, 14195 Berlin, Germany \\ e mail: menzel@neurobiologie.fu berlin.de \\ P. Szyszka \\ Department of Biology, Neurobiology, University of Konstanz, \\ Universitätsstraße 10, 78457 Constance, Germany
}

\author{
Abbreviations \\ GABA $\gamma$-Aminobutyric acid \\ cKC Clawed Kenyon cell \\ MB Mushroom body \\ PCT Protocerebral-calycal tract \\ BMI Bicuculline methiodide \\ PTX Picrotoxin \\ CGP CGP54626 \\ ROI Region of interest
}

\section{Introduction}

The mushroom bodies (MB) in the insect brain are higher-order integration centers for multisensory input and are also involved in learning and memory formation. Olfactory coding and learning are known to be an essential property of MB functions both in Drosophila (Davis 1993; Heisenberg 2003) and the honeybee (Szyszka et al. 2008; Menzel 2012). Here, we focus on MB intrinsic neurons, Kenyon cells (KC) of type 2 (clawed KC, cKC) (Mobbs 1982; Rybak and Menzel 1993; Strausfeld 2002) that arborize in the lip region of the MB. Odorants are coded as spatial and temporal patterns by a sparse population and time code (bees: Szyszka et al. 2005, 2008; locusts: Laurent et al. 2001; flies: Murthy et al. 2008; Turner et al. 2008; moths: Ito et al. 2008). Sparse coding in KCs depends on postsynaptic inhibition via synaptic GABA release (Papadopoulou et al. 2011; Lei et al. 2013), high action potential thresholds (Demmer and Kloppenburg 2009) and active dendritic conductance (Perez-Orive et al. 2002). The effect of these circuit and intrinsic properties is that $\mathrm{KCs}$ require coincident input from several first- 
order interneurons, the olfactory projection neurons, to respond to odorants (Perez-Orive et al. 2004; Jortner et al. 2007).

$\mathrm{GABA}_{\mathrm{A}}$ and $\mathrm{GABA}_{\mathrm{B}}$ receptors are abundantly expressed in the antennal lobes and mushroom bodies (Enell et al. 2007) and GABA-mediated inhibition has been shown in the olfactory pathway at the level of the antennal lobe and the level of the lip region in MB calyx. In the antennal lobe and $\mathrm{MB}, \mathrm{GABA}$ ergic local interneurons provide inhibitory input to all other neurons and are involved in odor coding and odor learning (locust: Leitch and Laurent 1996; Drosophila: Wilson and Laurent 2005; Seki et al. 2010; Silbering and Galizia 2007; Chou et al. 2010; Huang et al. 2010; honeybee: Stopfer et al. 1997; Bicker 1999; Sachse and Galizia 2002; Barbara et al. 2005; Choudhary et al. 2012). In the honeybee, putatively inhibitory MB extrinsic GABAergic neurons belong to the A3 feedback neurons (Rybak and Menzel 1993) of the protocerebral-calycal tract (PCT) (Bicker 1999; Deglise et al. 2002; Grünewald and Wersing 2008). PCT neurons converge both on KCs and on the olfactory projection neurons terminating on cKCs (Ganeshina and Menzel 2001), a property also known from other insects (Papadopoulou et al. 2011; Lei et al. 2013). In the bee, odorants responses in PCT neurons change during associative olfactory learning (Grünewald 1999b; Haehnel and Menzel 2010, 2012) and thus are expected to adapt their inhibitory action on $\mathrm{cKC}$ to the experience of the animal. Accordingly, the strength of the $\mathrm{cKC}$ responses changes with odorants learning (Szyszka et al. 2008).

Odorants of different concentrations can be distinguished and learned by bees (Pelz et al. 1997; Wright et al. 2009), as well as by Drosophila (Yarali et al. 2009). The neural mechanisms of concentration coding at the level of $\mathrm{KCs}$ are unknown. In locusts, KCs' responses to different concentrations can be concentration specific, concentration invariant or concentration dependent (Stopfer et al. 2003). In Drosophila the population of KCs responds in a concentration-invariant manner (Honegger et al. 2011). It is not clear whether and how GABAergic synaptic transmission is involved in concentration coding in the $\mathrm{MB}$, and it is not known whether different populations of KCs differ in their concentration dependence.

We investigated concentration coding in cKCs of the bee by measuring $\mathrm{Ca}^{2+}$ responses in the dendrites and somata separately in the two input regions of the $\mathrm{MB}$, the median and lateral calyces. Moreover, we tested whether ionotropic $\mathrm{GABA}_{\mathrm{A}}$ and metabotropic $\mathrm{GABA}_{\mathrm{B}}$ gated synaptic transmission is involved in the encoding of stimulus concentration and stimulus duration. Our data show that the population of KCs exhibits positive concentration-dependent odorant responses. Concentration dependence differed between the median and lateral calyces, implying different strength of gain control and thus probably different degree of sparsening between these two $\mathrm{KC}$ populations. $\mathrm{ON}$ responses were attenuated by $\mathrm{GABA}_{\mathrm{A}}$ and $\mathrm{GABA}_{\mathrm{B}}$ receptors mainly at higher odorant concentrations, and $\mathrm{OFF}$ responses were not affected by GABAergic transmission. Our data suggest that the sparsening of $\mathrm{KC}$ responses depends on at least two mechanisms: (1) GABA-dependent gain control of the projection neuron to $\mathrm{KC}$ transmission, and (2) GABA-independent shortening of $\mathrm{KCs}$ ' $\mathrm{ON}$ responses.

\section{Materials and methods}

Animal preparation and dye loading

Experimental procedures for in vivo $\mathrm{Ca}^{2+}$ imaging have been described elsewhere (Szyszka et al. 2005). In brief, foraging honeybees (Apis mellifera) were caught at the entrance of the hive, immobilized by chilling on ice, and fixed in a specially designed Plexiglas chamber using dental wax. The antennae were restrained from moving in front of the head capsule. Then the head capsule between the compound eyes and the ocelli was opened for dye injection. Clawed Kenyon cells (cKC) of the median or lateral calyx were retrogradely stained with a mixture of the $\mathrm{Ca}^{2+}$ sensor FURA-2 dextran (MW 10,000, Molecular Probes, Eugene, USA) and the fixable dye tetramethylrhodamine-dextran (MW 10,000, Molecular Probes, Eugene, USA) at a 10:1 ratio. For staining of cKCs the mixture was first picked up by the tip of a glass electrode broken to a tip diameter of about $10 \mu \mathrm{m}$. Next, the tip of the glass electrode was quickly stuck into $\mathrm{KC}$ axons projecting to the ventral median part of the $\alpha$-lobe, a region known to receive axon terminals from cKC (Mobbs 1982; Rybak and Menzel 1993). Then the head capsule was closed with a piece of cuticle, the animal was fed with sucrose solution, and the mixture of dyes was allowed to diffuse for at least $4 \mathrm{~h}$ or overnight during which the bee was kept in a dark and moist chamber. Before starting $\mathrm{Ca}^{2+}$ imaging, trachea and glands from the frontal brain surface were removed. The brain was covered with Ringer's solution $(130 \mathrm{mM} \mathrm{NaCl}, 6 \mathrm{mM} \mathrm{KCl}, 4 \mathrm{mM}$ $\mathrm{MgCl}_{2}, 5 \mathrm{mM} \mathrm{CaCl}, 160 \mathrm{mM}$ sucrose, $25 \mathrm{mM}$ glucose, 10 mM HEPES, pH 6.7, 500 mOsmol, all chemicals from Sigma Aldrich) and the animal was transferred to the microscope stage where experiments were performed within $1 \mathrm{~h}$. Following imaging, the head of the bee was dissected, fixed in $4 \%$ paraformaldehyde, cleared in methylsalicylate and imaged with a confocal laser scanning microscopy (TCS PS2, Leica, Wetzlar, Germany) at an excitation wavelength of $555 \mathrm{~nm}$ using a Leica $10 \times$ air objective for overview scans or a Leica $40 \times$ objective for image details. 
$\mathrm{Ca}^{2+}$ imaging

$\mathrm{Ca}^{2+}$ imaging was performed at approximately $25^{\circ} \mathrm{C}$. For ratiometric measurements, the $\mathrm{Ca}^{2+}$-sensitive dye FURA-2 was alternately excited at 340 and $380 \mathrm{~nm}$. Emitted fluorescence was measured using a $410 \mathrm{~nm}$ dichroic mirror and a $440 \mathrm{~nm}$ long pass filter. Images were recorded with a sampling rate of $6 \mathrm{~Hz}$ using a TILL-Photonics imaging setup (Till Vision, Gräfelfing, Germany) mounted onto a conventional upright fluorescence microscope (Axioskop, Zeiss, Oberkochen, Germany). Exposure time for each wavelength was adjusted for each animal according to the quality of the obtained signal.

Recordings started $2 \mathrm{~s}$ before odorant onset (odorant stimulus: $3 \mathrm{~s}$ or less) and lasted for $10 \mathrm{~s}$. $\mathrm{Ca}^{2+}$ signals were recorded through a $20 \times 0.95 \mathrm{~W}$ dip objective (Olympus, Tokyo, Japan) or a $60 \times$ objective (for individual somata, Fig. 1d) and a CCD camera (Visicam, Visitron Systems $\mathrm{GmbH}$, Puchheim, Germany). For the $20 \times$ objective, spatial resolution was $2.2 \times 2.2 \mu \mathrm{m} /$ pixel $(160 \times 120$ pixels, $4 \times$ binning) resulting in an imaged area covering $350 \times 260 \mu \mathrm{m}$. For the $60 \times$ objective the spatial resolution was $0.7 \times 0.7 \mu \mathrm{m} /$ pixel $(160 \times 120$ pixels, $4 \times$ binning) resulting in an imaged area of $112 \times 84 \mu \mathrm{m}$. cKC dendrites were imaged on the accessible, anterior surface of the MB. The minimal time between two measurements was $90 \mathrm{~s}$.

\section{Odorant stimulation}

Naturally occurring odorants (primary and secondary alcohols, ketones and aldehydes, named in the figures, all from Sigma Aldrich, Germany), pure or diluted in paraffin oil (FLUKA, Buchs, Switzerland) at different ratios, were delivered to both antennae of the animals using a computer-controlled, custom-made olfactometer adapted from (Galizia et al. 1997). Odorant-loaded air was injected into a permanent airstream resulting in a further 1:10 dilution. Stimulus duration was $3 \mathrm{~s}$ except when mentioned otherwise. Air was permanently exhausted by a tube behind the preparation.

\section{Pharmacology}

Different GABA receptor antagonists were used to investigate the influence of GABA-mediated transmission in the olfactory pathway on $\mathrm{Ca}^{2+}$ activity in the $\mathrm{MB}$. The following pharmaceuticals were applied after an initial control experiment in the untreated animals: $150 \mu \mathrm{l}$ of the $\mathrm{GABA}_{\mathrm{A}}$ antagonists picrotoxin $\left(10^{-5} \mathrm{M}\right.$, PTX, Sigma Aldrich, Germany) or bicuculline methiodide $\left(10^{-5} \mathrm{M}\right.$, BMI, Sigma Aldrich, Germany), and the GABA $_{\mathrm{B}}$ antagonist CGP54626 $\left(5 \times 10^{-4} \mathrm{M}\right.$, CGP, Tocris Bioscience, USA). The drugs were bath applied to the bee brain manually. $100 \mathrm{mM}$ stock solutions of PTX and CGP were prepared in DMSO. BMI stock was prepared in water. For final concentration the stocks were diluted in the same Ringer as used before. The dilution of stock solution in Ringer was 1:10,000 and 1:5,000, respectively. At this concentration, DMSO had no effect on $\mathrm{Ca}^{2+}$ responses in cKCs (Fig. 3a). Measurements started $10 \mathrm{~min}$ after drug application.

\section{Data acquisition and analysis}

A custom-written routine in IDL (RSI, Boulder, CO, USA) was applied to calculate the ratio of fluorescence intensities measured at 340 and $380 \mathrm{~nm}$ excitation wavelengths for each pixel. The average fluorescence intensity before odorant onset was subtracted. This leads to the value of $\Delta F$ with $F=F_{340} / F_{380}$. For visualization of neuronal activity, color-coded pictures were generated using IDL software. Regions of interest (ROI) were defined corresponding to the MB-lip region of the MB (Mobbs 1982; Rybak and Menzel 1993). The temporal dynamic was calculated by averaging values of all pixels inside the selected ROI. $\Delta F$ over $1 \mathrm{~s}$ (6 frames) after stimulus onset was averaged for determining dose response curves. Response strength was calculated as $\Delta F$ that reflects changes of the intracellular $\mathrm{Ca}^{2+}$ concentration, which are well correlated with spike activity as shown in the honeybee (Galizia and Kimmerle 2004). For quantitative analysis ON responses were calculated as the mean $\Delta F$ during $1 \mathrm{~s}$ after odorant onset (frames 12-17), except for Fig. 4 where the mean during $3 \mathrm{~s}$ after odorant onset was taken (frames 12 29) and Fig. 5e, where the response maximum was taken. OFF responses were calculated as the maximum during $2 \mathrm{~s}$ after stimulus termination (frames 30 41) minus the response at stimulus end (frame 29). Quantitative data analysis was performed in MicrosoftExcel and MATLAB (Mathworks Cooperation, Natick, USA). Error bars indicate the standard error of the mean (s.e.m.)

\section{Results}

Odorant response dynamics and concentration dependence in Kenyon cells

The procedure of dye filling applied in this study ensured selective staining of cKCs. The selective staining of cKCs was verified by confocal scanning microscopy of $\mathrm{KCs}$ ' morphology after each $\mathrm{Ca}^{2+}$ imaging experiment (Fig. 1a, b). The registration of the $\mathrm{cKC}$ into the standard brain atlas of the honeybee shown in Fig. 1a was based on a representative example of a confocal image stack (Fig. 1b) from 

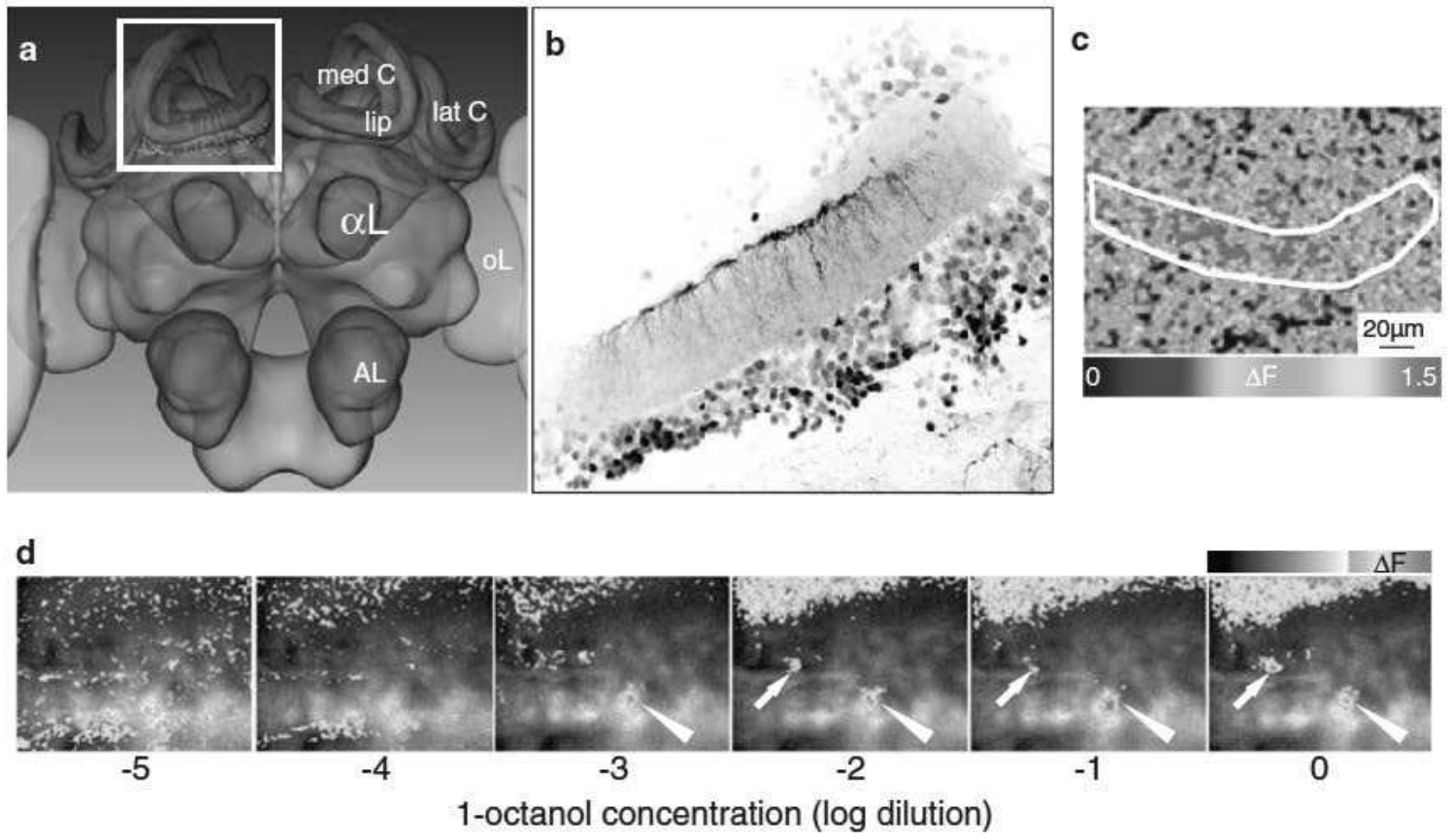
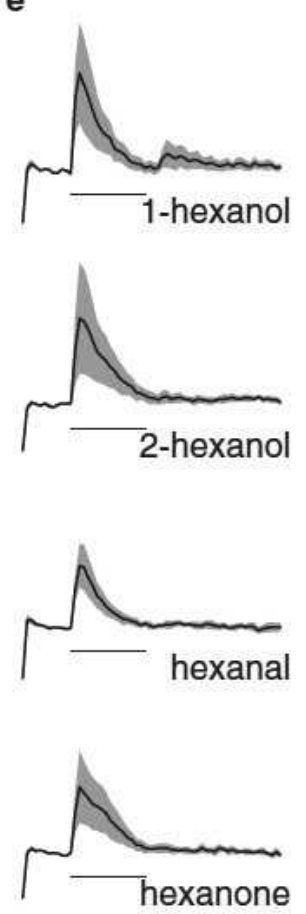
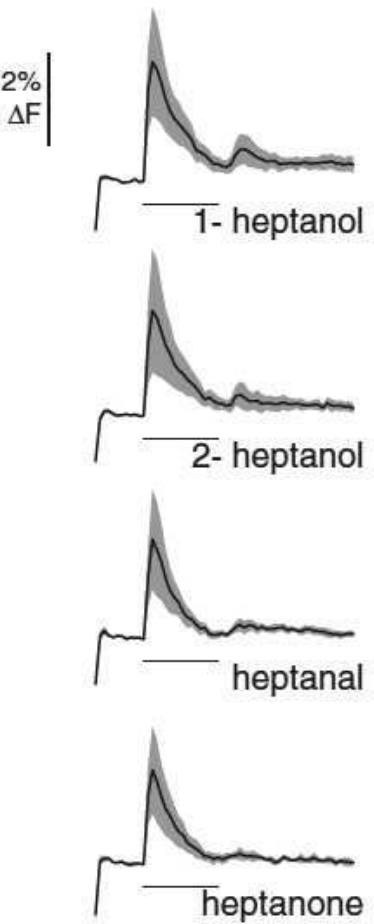
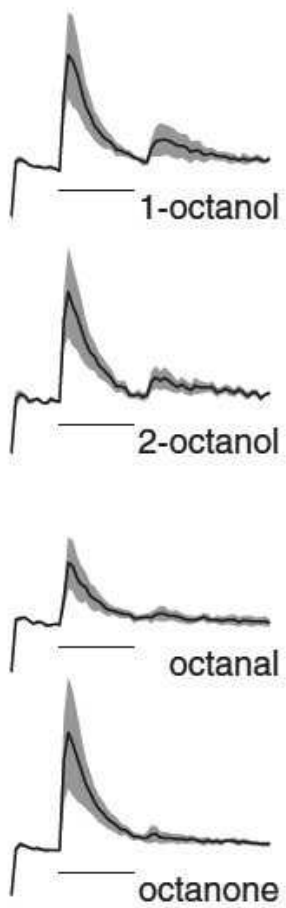
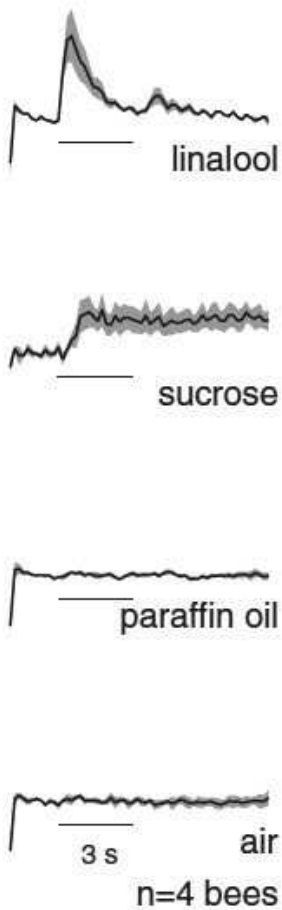

the fixed and cleared preparation after the $\mathrm{Ca}^{2+}$ imaging experiment. $\mathrm{Ca}^{2+}$ imaging was performed on the somata and dendrites of $\mathrm{cKCs}$ in the lip region of the MB calyx. Figure 1c shows a color-coded image of the fluorescence changes during odorant stimulation. $\mathrm{cKC}$ dendrites responding to the olfactory stimuli were localized in the lip region of the $\mathrm{MB}$. The region of $\mathrm{cKC}$ dendrites was marked as region of interest (ROI). For quantitative analyses of $\mathrm{Ca}^{2+}$ responses, the values of all pixels inside an ROI were averaged. Figure 1d shows color-coded odorant responses superimposed on the raw fluorescence in the somatic region of $\mathrm{cKC}$. The white arrowhead and the white arrow indicate somata which responded reliably to different concentrations of 1-octanol. Notice that the soma marked 
4 Fig. 1 Odorant evoked calcium signals in cKC dendrites and somata. a The honeybee standard brain with engrafted $\mathrm{cKC}$ somata and axons within the lip. The reconstruction of the neurons is based on confocal scan shown in (b). $A L$ antennal lobe, $o L$ optical lobe, $\alpha L \alpha$ lobe, med $C$ median calyx, lat $C$ lateral calyx. b Confocal scan of the right median MB lip showing Rhodamin backfill staining of cKC via the $\alpha$ lobe. Dendrites and somata of filled cKC are visible within and next to MB lip neuropil. c Representative example of a color coded odorant response (single frame) in the median $\mathrm{MB}$ lip during stimulation with 1 octanol $\left(10^{-2}\right)$. The region of interest (ROI) used for quantifying signals is outlined. A $20 \times$ objective was used. Color code indicates change of intracellular $\mathrm{Ca}^{2+}$ concentration $\Delta F$ (red: high concentration, blue: low concentration, see scale at the right side). d Images of responses to pulses of the same odorant (1 octanol) at different concentrations showing that two individual somata of cKCs (white arrowhead and white arrow) respond rather equally to different concentrations, whereas the dendrites within the ROI increase their responses with concentration. One soma (white arrowhead) responds to the four highest odorant concentrations, while the other (white arrow) responds to the three highest concentrations. Here, a $60 \times$ objective was used and therefore only a part of the evaluated ROI is visible. The false color is scaled separately for each picture; thus pictures become noisier with smaller responses. e Averaged responses of cKCs to different stimuli (13 odorants of a $10^{-2}$ concentration, control stimuli and sucrose). The mean responses from four animals during three repeated stimuli were averaged. The gray areas give s.e.m.; the black bars indicate the $3 \mathrm{~s}$ long stimuli

with the white arrowhead responded to all concentrations above $10^{-4}$, whereas that marked with the white arrow responded only to higher concentrations $\left(>10^{-3}\right)$ indicating that increasing concentrations recruited more cKCs, and cKCs responding to lower concentrations did not drop out at higher concentrations. Thus, these two KCs were not tuned to specific concentrations, but rather the population of cKCs responding to the particular odorant increased with concentration. Correspondingly, the $\mathrm{Ca}^{2+}$ response of the dendritic area (Figs. 1d, 4c) became stronger and broader with increasing concentration.

We tested 13 different odorants, namely primary and secondary alcohols, ketones and aldehydes (1-hexanol, 2-hexanol, hexanal, hexanone, 1-heptanol, 2-heptanol, heptanal, heptanone, 1-octanol, 2-octanol, octanal, octanone and linalool) with six, seven or eight carbon atoms plus linalool as a commonly used odorant in odor-conditioning experiments with honeybees, as well as two control stimuli (pure air and paraffin oil) and sucrose. The sucrose solution was presented to the proboscis. cKCs' dendritic odorant responses were restricted to the lip region and exhibited the characteristic phasic response with a fast increase at odorant onset, a slightly slower decay and weaker OFF responses (Fig. 1e). No inhibitory responses were observed with any of the applied stimuli. Most responses for different odorants and concentrations differed predominantly in their absolute strength, but not in their kinetics. After stimulus termination, OFF responses were visible for 9 out of 13 odorants. OFF responses were stronger for primary and secondary alcohols than for aldehydes and ketones, and chemicals with a carbon chain length of seven or eight evoked stronger OFF responses than chemicals with a carbon chain length of six, indicating that OFF responses increased with increasing carbon chain length. ON and OFF responses evoked similar spatial activity patterns which indicates that they were generated by the same cells. Generally, cKC did not show spontaneous activity.

The response kinetics to sucrose (and to light onset at the beginning of the recording) were different from odorant response kinetics. The response decay during sucrose stimuli was slower compared to that during olfactory stimulation and there was no OFF response (Fig. 1e). The increase in intracellular $\mathrm{Ca}^{2+}$ at light onset was not clearly limited to the lip region, but rather spread over the whole calyx (data not shown).

\section{$\mathrm{ON}$ and $\mathrm{OFF}$ responses increase with increasing} odorant concentration

We recorded dendritic cKC responses to different concentrations of the same odorant. Figure 2a shows averaged responses in the dendritic area of the median and lateral calyx upon 1-octanol stimulation. The time course in response to different odorant concentrations was always phasic, but differed in their maximal amplitudes: increasing odorant concentrations lead to higher response amplitudes for both ON and OFF responses. Even the lowest concentration $\left(10^{-5}\right)$ induced a small response. A positive correlation between odorant concentration and $\mathrm{Ca}^{2+}$ activity in the dendritic region of cKCs was found for all odorants. Thus, either the number of responding cKCs increased with increasing odorant concentration or the response strength of responding cKCs increased, or both.

Next, we tested whether the sequence of odorant stimuli (increasing or decreasing concentrations) had an influence on the response, indicating an adaptation or a repetition effect and found no such differences (Fig. 2b). We then chose a descending order starting with the highest dose and applying five or six odorant concentrations ranging from pure odorant to a four or five times logarithmic dilution, each concentration getting further diluted in the permanent carrier airstream of the olfactometer by 1:10.

We selected two odorants for further experiments aiming to unravel the role of GABAergic synaptic transmission to odorant concentration processing. Hexanal was chosen as an odorant that did not evoke OFF responses (Fig. 2c) and 1-octanol was chosen because it reliably elicited OFF responses (Fig. 2d). The lateral and median calyces were imaged in different bees. cKCs' population response to hexanal and 1-octanol showed positive concentration dependence and did not show 

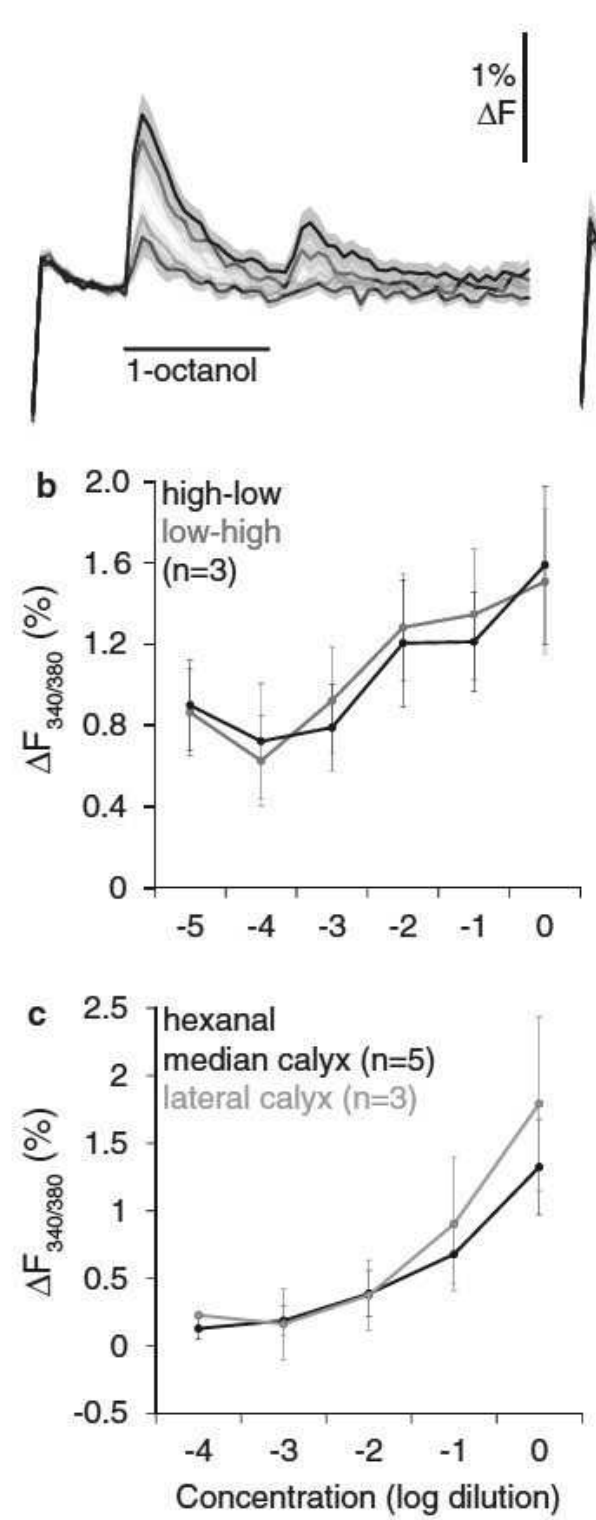

Fig. 2 The population response of Kenyon cells shows positive concentration dependence and differs between the median and lateral calyces. a Dendritic calcium responses in $\mathrm{cKCs}$ of the median and lateral calyx to different concentrations of 1 octanol ranging from a $10^{-5}$ dilution ( 5 ) to pure odorant ( 0 ). Average signals over $n$ bees (mean \pm s.e.m.). All bees were stimulated with all concentrations expect for the lowest concentration, which was presented in a subset of bees. The lower $n$ value refers to the lowest concentration. Average signals of 12 bees. b Dose response curves for increasing (low high) and decreasing (high low) concentration series. For both concentra tion series, there was a positive concentration dependence and no difference between dose response curves could be detected (two way repeated measurement ANOVA; $F_{\text {sequence }} 0.51, p \quad 0.55$;

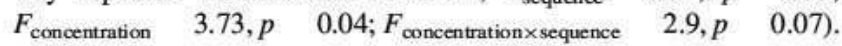

saturation at the highest concentration, indicating a wide dynamic range of concentration coding. In both calyces, the dose response curves were sigmoidal, and for higher lateral calyx $(n=9-12)$
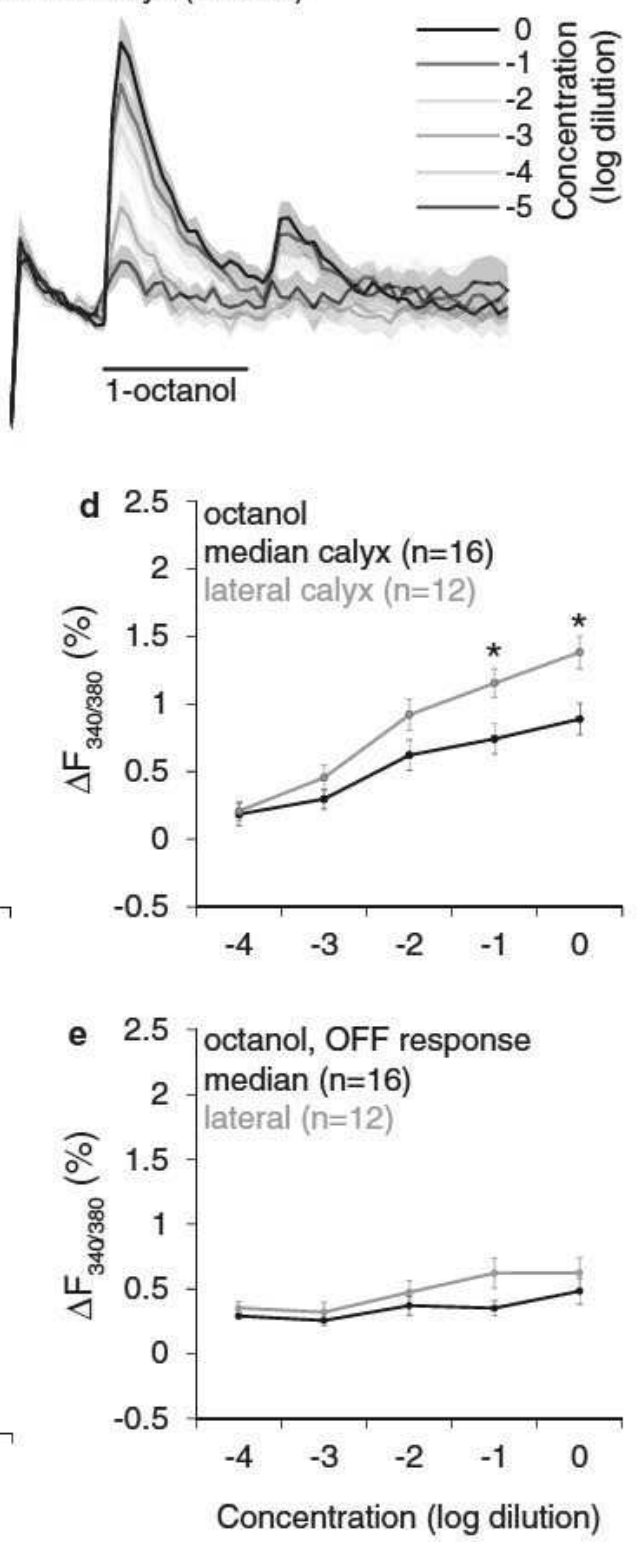

One increasing and one decreasing concentration series per bee. The odorant was hexanal (one bee) or octanol ( 2 bees). c Dose response curves for hexanal were similar in both calyces (two way repeated measurement ANOVA; $F_{\text {calyx }} \quad 0, p \quad 0.99 ; F_{\text {concentration }} 27.7$, $\left.p<0.001 ; \quad F_{\text {concentration } \times \text { calyx }} 2, \quad p \quad 0.13\right)$. d Dose response curves for octanol were steeper in the lateral calyx (two way repeated measurement ANOVA; $F_{\text {calyx }} \quad 5.3, p \quad 0.03 ; F_{\text {concentration }} \quad 73.2$, $p<0.001 ; F_{\text {concentration } \times \text { calyx }} 4.3, p \quad 0.003$ ). e OFF responses showed a positive concentration dependence, but no difference between calyces (two way repeated measurement ANOVA; $F_{\text {calyx }}$ $1.86, p \quad 0.18 ; F_{\text {concentration }} \quad 11, p<0.001 ; F_{\text {concentration } \times \text { calyx }} 1.7$, $p$ 0.16). Values are the mean \pm s.e.m. over animals. Stars indicate significance between concentration curves $\left({ }^{*} p<0.05\right)$. Holm Sidak post hoc tests for pairwise comparisons

odorant concentrations the response strength was larger in the lateral calyx. OFF responses after 1-octanol stimulation also increased with concentration, but there was no 
statistically significant difference between the calyces (Fig. 2e).

$\mathrm{GABA}_{\mathrm{A}}$ receptor-mediated inhibition attenuates $\mathrm{ON}$ responses to higher odorant concentration

cKCs receive not only excitatory input via projection neurons, but also inhibitory input via recurrent GABA-ir neurons (Grünewald 1999a; Ganeshina and Menzel 2001) projecting back from the MB lobes to its calyces. Thus, excitatory and inhibitory inputs may contribute to the dynamic of cKC responses. We therefore asked whether GABA-mediated inhibition has an impact on cKC ON and OFF responses and on their concentration dependence. First, we tested if the solvent DMSO at the used dilution of 1:5,000 affected odorant response and found no change in the strength or concentration dependency of cKC responses (Fig. 3a). Bath application of the $\mathrm{GABA}_{\mathrm{A}}$ receptor antagonist PTX increased ON response amplitudes at higher odorant concentrations both in the lateral and median calyces (Fig. 3b, c). Notably, the concentration dependence was still apparent during PTX application. Also the response dynamics did not change (see below). BMI, another $\mathrm{GABA}_{\mathrm{A}}$ antagonist acting via a different mechanism (Rotte et al. 2009), had no significant effect on cKCs' ON response strength or concentration dependence (Fig. 3d). Different to $\mathrm{ON}$ responses, OFF responses did not change significantly during application of the $\mathrm{GABA}_{\mathrm{A}}$ receptor antagonists PTX and BMI (Fig. 3e, f; to reveal potential GABA effects on OFF responses, responses to all odorants and from both calyxes were pooled). Thus, cKCs' ON responses, but not their OFF responses, appeared to be attenuated by $\mathrm{GABA}_{\mathrm{A}}$ receptor-mediated inhibition.

$\mathrm{GABA}_{\mathrm{B}}$ receptor-mediated inhibition slightly attenuates $\mathrm{ON}$ responses

We next asked whether $\mathrm{GABA}_{\mathrm{B}}$ receptor blockers affect the concentration dependence of cKCs odorant responses. The drug CGP is an antagonist of the metabotropic $\mathrm{GABA}_{\mathrm{B}}$ receptor in the mammalian nervous system (Asay and Boyd 2006). This drug is also effective in honeybees and other insects (Wilson and Laurent 2005; Root et al. 2008, Rotte et al. 2009). In the median calyx, the application of CGP increased ON responses to odorant concentrations above $10^{-3} \mathrm{M}$ (Fig. 4a). The same tendency was seen for the lateral calyx (Fig. $4 b$, in all bees all responses to concentration above -3 were higher during CGP application). Although there was no significant difference for the overall effect of the CGP treatment, there was an interaction between the effect of odorant concentration and CGP application. The increase in $\mathrm{ON}$ response strength in the median calyx during CGP treatment was less pronounced as compared to the increase after PTX treatment. Figure $4 \mathrm{c}$ shows representative images of $\mathrm{ON}$ responses to different odorant concentrations before and after application of CGP. OFF responses were not affected by CGP treatment (Fig. 4d). Thus, cKC ON responses, but not their OFF responses, appeared to be attenuated by $\mathrm{GABA}_{\mathrm{B}}$ receptor-mediated inhibition.

$\mathrm{GABA}_{\mathrm{A}}$ receptor-mediated inhibition does not influence the temporal resolution of Kenyon cells

cKCs' response dynamics suggest a sequence of excitatory and inhibitory inputs. When applying linalool pulses of varying length between 0.1 and $3 \mathrm{~s}$, the odorant responses were equally long (Fig. 5a), suggesting that cKCs respond mainly to the odorant onset and not during steady-state odorant stimulation. However, OFF responses depended on the stimulus length, and they were not generated when stimuli lasted $<3 \mathrm{~s}$. The fast response dynamics is not an artifact of the dye, as the used Fura- 2 is well capable of resolving slower $\mathrm{Ca}^{2+}$ dynamics which follows spiking activity in honeybees' projection neurons (Galizia and Kimmerle 2004) and resolves the slower response dynamics as seen in cKCs' sugar response (Fig. 1e).

Therefore, we next tested KCs' ability to resolve double pulses of $1 \mathrm{~s}$ long hexanal stimuli (Fig. 5b). We chose hexanal because hexanal did not elicit OFF responses even at longer pulses (Fig. 1e). We found that gaps down to $0.1 \mathrm{~s}$ were sufficient to evoke the same maximal odorant responses to the second pulse. Thus, $\mathrm{cKCs}$ are capable of resolving rapid fluctuations of odorant stimuli.

We then asked whether the temporal resolution of $\mathrm{cKC}$ response to a double pulse of one odorant is influenced by the $\mathrm{GABA}_{\mathrm{A}}$ receptor blocker PTX. A temporal gap of $167 \mathrm{~ms}$ and a pulse length of $333 \mathrm{~ms}$ were used. The response strength of $\mathrm{cKCs}$ decreased from the first to the second pulse (Fig. 5c). Blocking $\mathrm{GABA}_{\mathrm{A}}$ receptors with PTX increased the overall response strength. However, the response dynamic (Fig. 5d) and the response decrease during the second pulse remained unaffected (Fig. 5e). Thus, the temporal resolution of KCs odorant responses did not depend on GABAergic inhibition via PTX sensitive receptors.

\section{Discussion}

In this work, we studied the effect of odorant concentration and the application of GABA receptor antagonists on odorant-evoked responses in honeybee clawed KC (cKC). These higher-order interneurons in the olfactory pathway receive excitatory input from the antennal lobe via 

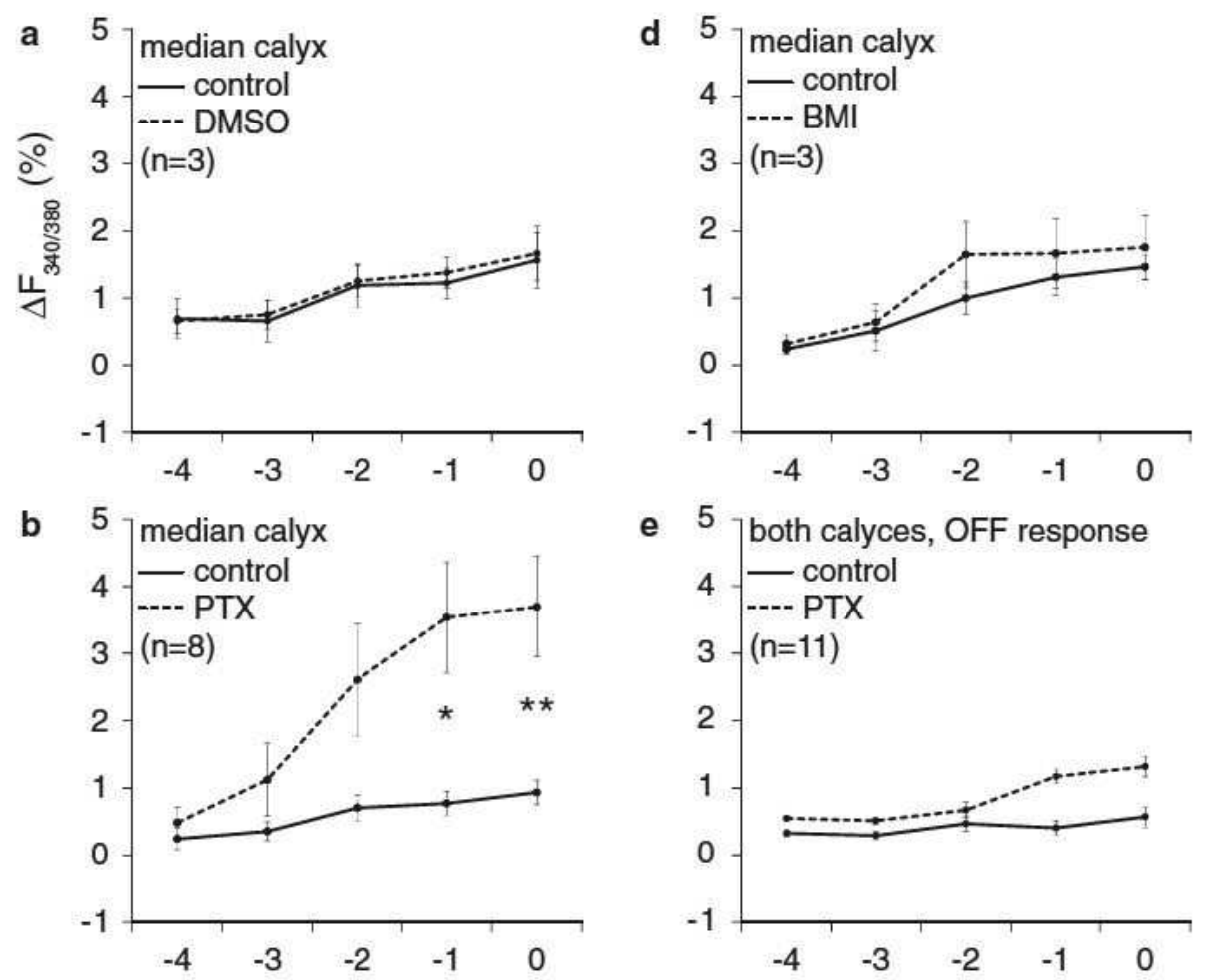

e 5 both calyces, OFF response
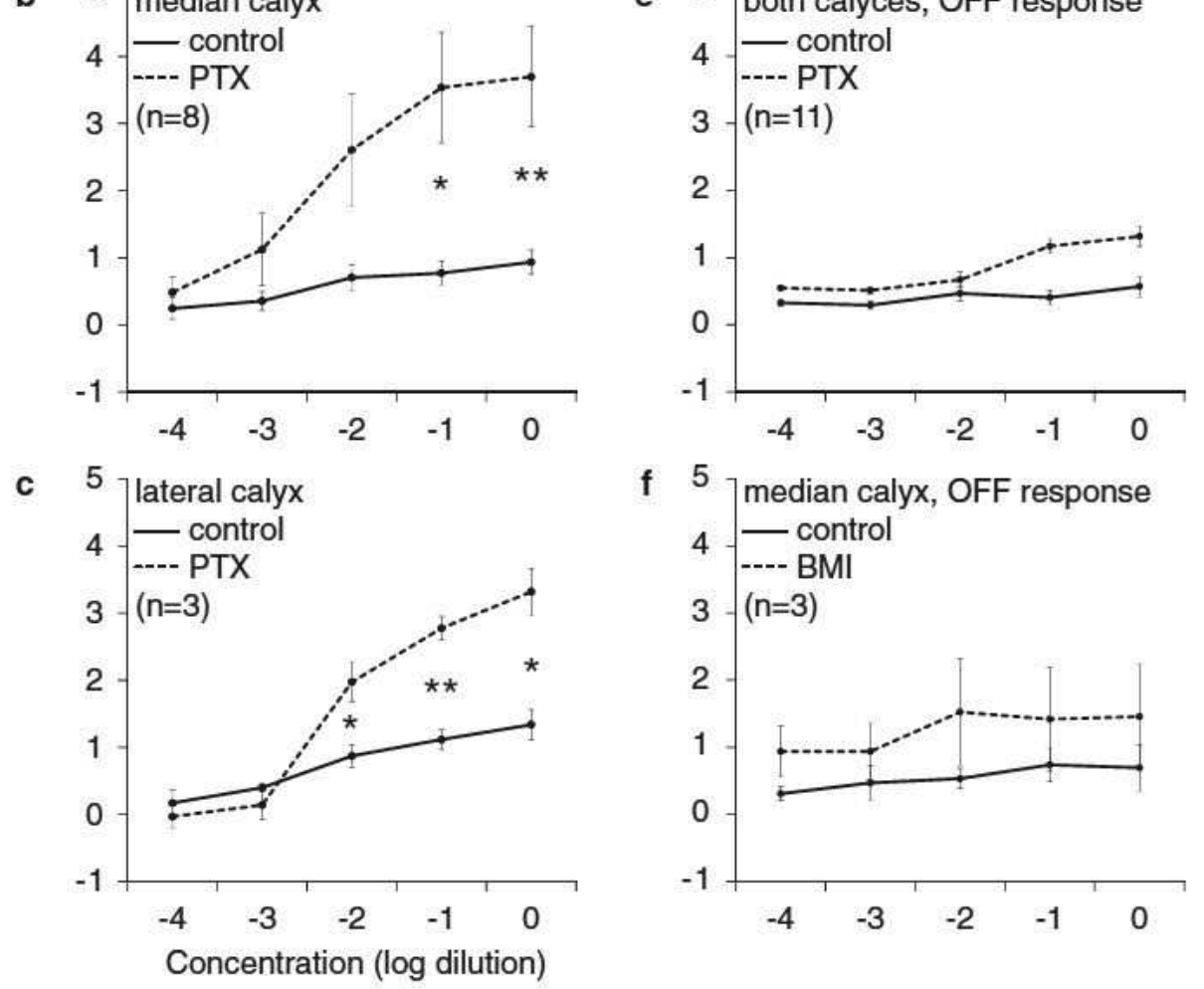

f 5 median calyx, OFF response

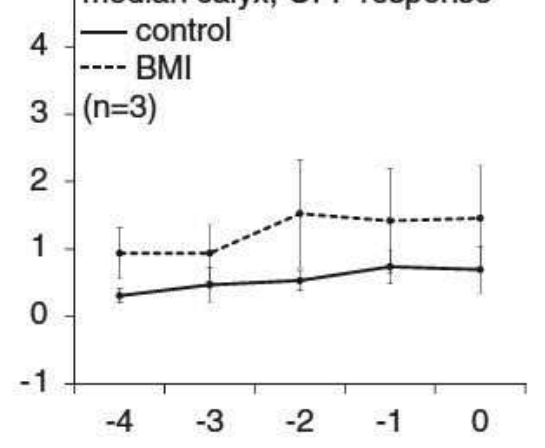

Fig. 3 Blocking of $\mathrm{GABA}_{\mathrm{A}}$ receptors steepens dose response curves for Kenyon cells' ON responses. a Dose response curves of odorant responses in the median calyx did not differ before (control) and during application of DMSO (two way repeated measurement ANOVA; $F_{\text {treatment }} \quad 0.4, p \quad 0.6 ; F_{\text {concentration }} \quad 3.8, p \quad 0.05$; $\begin{array}{lll}F_{\text {concentration } \times \text { treatment }} & 0.5, p & 0.76) \text {. b Dose response curves for }\end{array}$ 1 octanol in the median calyx before (control) and during application of $10^{-5} \mathrm{M}$ PTX. Odorant responses to concentrations above $10^{-3}$ increased during PTX treatment (two way repeated measurement ANOVA; $F_{\text {treatment }} \quad 8.3, p \quad 0.02 ; F_{\text {concentration }} \quad 26.5, p<0.001$;

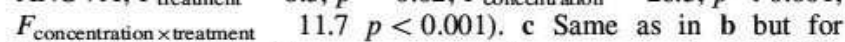
the lateral calyx (two way repeated measurement ANOVA;

projection neurons and inhibitory input from GABAergic feedback neurons (Ganeshina and Menzel 2001) within the lip of the MB calyces. In the MB of the locust, GABAergic feedback neurons increase the spiking threshold of KCs (Papadopoulou et al. 2011). However, it is not known whether and how GABAergic feedback neurons affect

$F_{\text {treatment }} \quad 31.7, \quad p \quad 0.03 ; \quad F_{\text {concentration }} \quad 63.3, \quad p<0.001$; $\left.F_{\text {concentration } \times \text { treatment }} 44.2, p<0.001\right)$. d Same as in b but $10^{-5}$ $\mathrm{M}$ BMI was used as $\mathrm{GABA}_{\mathrm{A}}$ antagonist (two way repeated measurement ANOVA; $F_{\text {treatment }} 2, p \quad 0.29 ; F_{\text {concentration }} 18$,

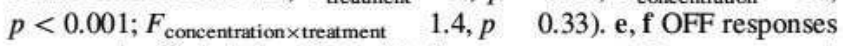
were not affected by PTX (e) (two way repeated measurement ANOVA; $\left.F_{\text {treatment }} \quad 1.2, p \quad 0.3 ; F_{\text {concentration }} \quad 2, p \quad 0.11\right)$ or BMI treatment (f) (two way repeated measurement ANOVA; $\begin{array}{lllll}F_{\text {treatment }} & 1.9, p & 0.3 ; F_{\text {concentration }} & 2.2, p & 0.16) \text {. Values are }\end{array}$ the mean \pm s.e.m. over animals. Stars indicate significance across concentration curves $\left({ }^{*} p<0.05,{ }^{*} p<0.01\right)$. Holm Sidak post hoc tests for pairwise comparisons

KCs' temporal odorant response properties, such as response duration, OFF response generation and temporal resolution. Here, we show that GABAergic inhibition in the olfactory pathway attenuates $\mathrm{cKC}$ responses to higher odorant concentration, while it does not affect cKCs' temporal response properties. 

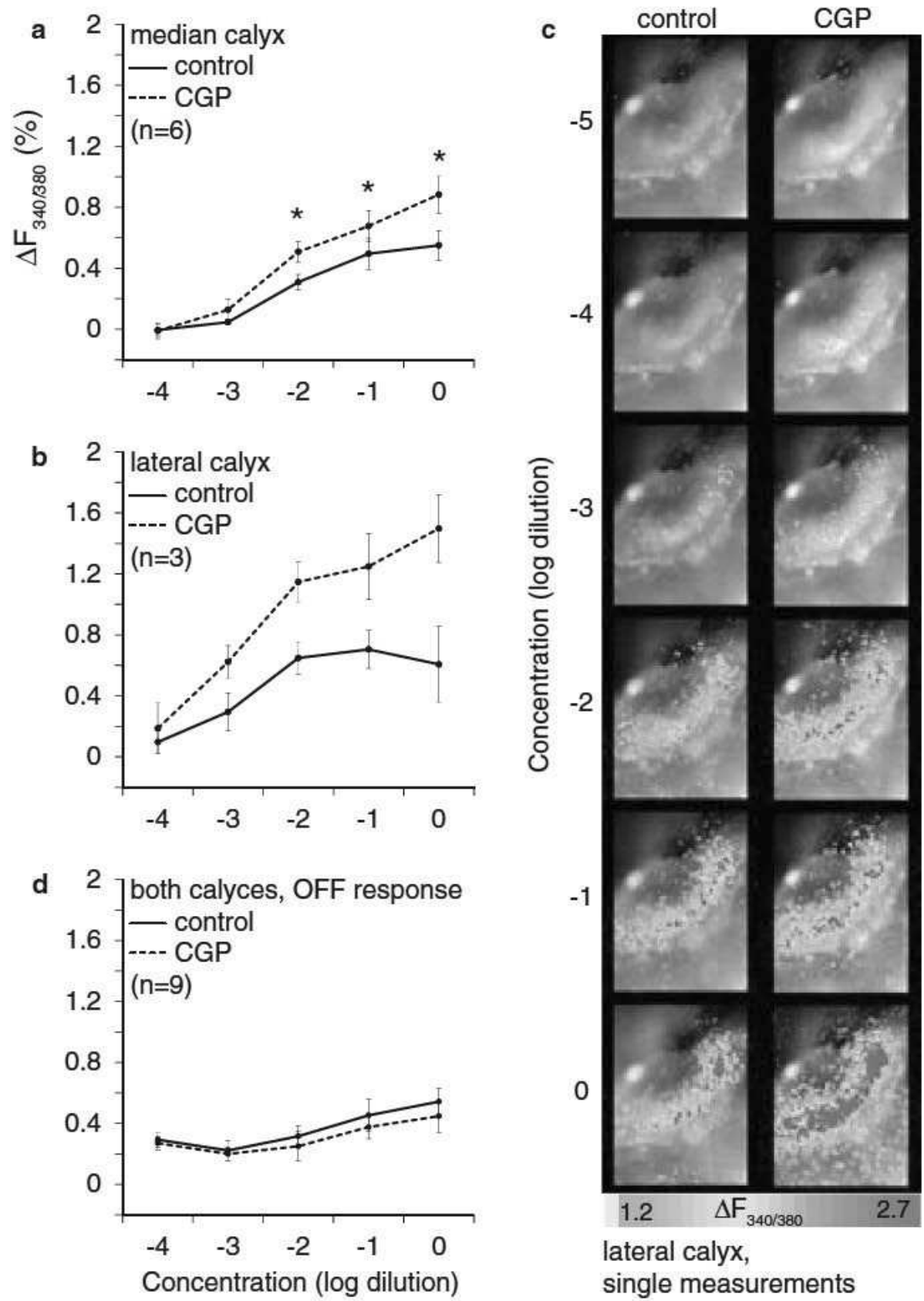

lateral calyx,
single measurements

Fig. 4 Blocking of $\mathrm{GABA}_{\mathrm{B}}$ receptors steepens dose response curves for Kenyon cells' ON responses. a Dose response curves for 1 octanol ON responses in the median calyx before (control) and during application of $5 \times 10^{-4} \mathrm{M} \mathrm{CGP}$. ON responses to concentra tions equal or above $10^{-2}$ increased during CGP treatment (two way repeated measurement ANOVA; $F_{\text {treatment }} 12.37, p$ 0.017; $F_{\text {concentration }} 29.9, \quad p<0.001 ; \quad F_{\text {concentration } \times \text { treatment }} 3.4$, $p \quad 0.028)$. b Same as in a but for the lateral calyx. There was no significant difference for the overall effect of CGP treatment. However, there was an interaction between the effect of concentration and treatment (two way repeated measurement ANOVA;

$F_{\text {treatment }} 2.15, \quad p \quad 0.239 ; \quad F_{\text {concentration }} 7.38, \quad p \quad 0.003$; $\left.F_{\text {concentration } \times \text { treatment } 3.89, p} 0.03\right)$. c Color coded odorant response superimposed on the raw fluorescence of a representative example of $\mathrm{ON}$ responses in the right lateral calyx upon stimulation with different concentrations before and during application of CGP. d OFF responses were not affected by CGP (two way repeated measurement ANOVA; $F_{\text {treatment }} \quad 0.4, p \quad 0.53 ; F_{\text {concentration }} \quad 8.4$, $\left.p<0.001 ; F_{\text {concentration } \times \text { treatment }} 0.3, p \quad 0.87\right)$. Values are the mean \pm s.e.m. over animals. Stars indicate significance across concentration curves $\left({ }^{*} p<0.05\right)$. Holm Sidak post hoc tests for pairwise comparisons 

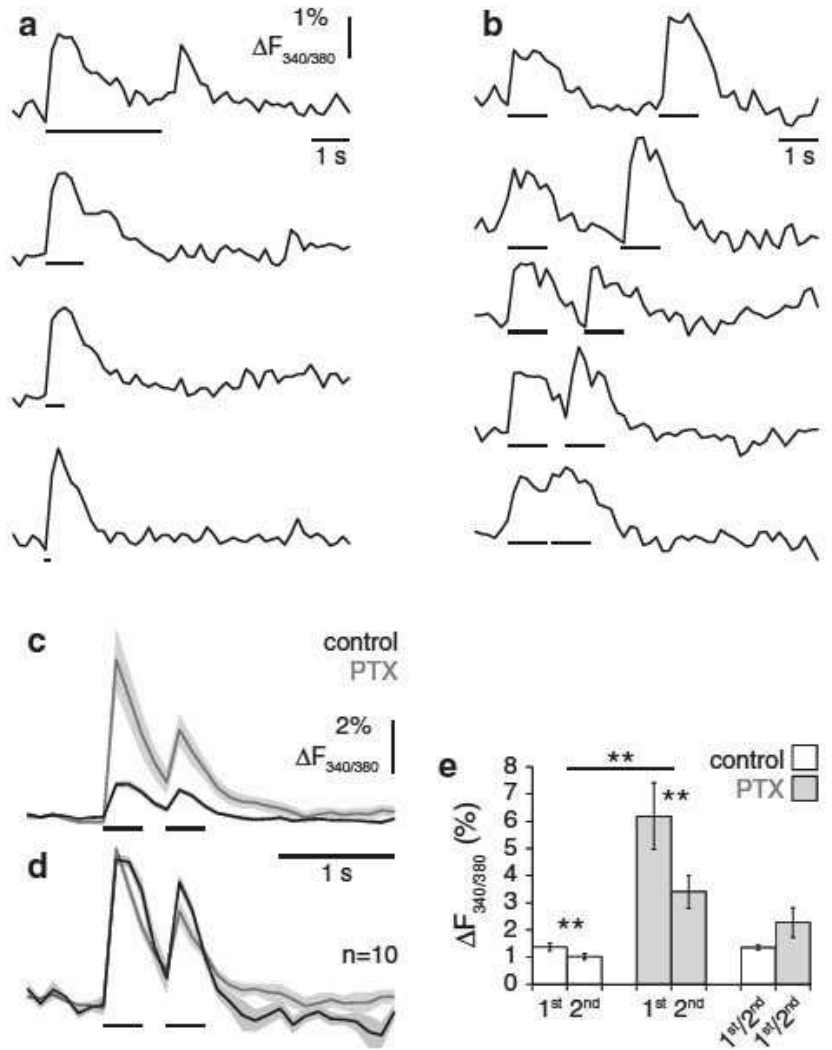

Fig. 5 Kenyon cells' capability to track odorant pulses does not depend on $\mathrm{GABA}_{\mathrm{A}}$ receptor mediated inhibition. a A single odorant stimulus (linalool) was presented at different stimulus durations ( 0.1 , $0.5,1$ or $3 \mathrm{~s}$ ). Only a long stimulus ( $3 \mathrm{~s}$, upper trace) evokes an OFF response. $\mathbf{b}$ A double pulse of the same odorant (hexanal, each pulse $1 \mathrm{~s})$ was applied with gap lengths $(0.1,0.5,1,2$ or $3 \mathrm{~s})$. Response traces were normalized to the odorant onset of the first stimulus. c Mean $\mathrm{KC}$ responses to double pulses (pulse length: $333 \mathrm{~ms}$, gap: $167 \mathrm{~ms}$ ). Shaded area indicates s.e.m. Bars indicate odorant pulses. $N \quad 10$ stimulations in 5 bees. d Same data as in c, but normalized to the maximum of the response to the first pulse. e Response maxima during the first and second pulses (mean, s.e.m.). The response maximum decreased from the first to the second pulse, and they increased during PTX treatment. However, PTX treatment did not change the ratio between the response maxima during the first and second pulse (two way repeated measurement. ANOVA; $\begin{array}{lllllll}F_{\text {treatment }} & 19.7, \quad p & 0.002 ; & F_{\text {pulse }} & 16.1, \quad p & 0.003 ;\end{array}$ $F_{\text {pulsextreatment }} 11, p \quad 0.009$; Holm Sidak post hoc tests for pairwise comparisons; ${ }^{* *} p<0.01$ )

\section{General response properties of clawed Kenyon cells}

Our data confirmed the results of previous $\mathrm{Ca}^{2+}$ imaging studies of odorant-induced activity in cKC dendrites in the lip which revealed sparse responses, both at the temporal and population level (Szyszka et al, 2005, 2008). In this respect, they share the properties of $\mathrm{KCs}$ in the locust (Laurent 2002; Perez-Orive et al. 2002) and Drosophila (Wang et al. 2004; Murthy et al. 2008; Turner et al. 2008): a given odorant activates only a small proportion of highly odorant-specific KCs. Furthermore, in contrast to the presynaptic projection neurons, KCs responded with brief and phasic ON responses and often exhibited OFF responses after stimulus termination. Our finding of $\mathrm{GABA}_{\mathrm{A}}$ and $\mathrm{GABA}_{\mathrm{B}}$ receptor-mediated reduction of $\mathrm{ON}$ responses is in line with previous studies about the neural mechanisms underlying KCs' sparse odorant code. It has been concluded that GABA receptor-mediated transmission onto KC (Papadopoulou et al. 2011; Lei et al. 2013) in combination with KCs' high action potential thresholds (Demmer and Kloppenburg 2009) and active dendritic conductance (Perez-Orive et al. 2002, 2004) requires multiple convergent and coincident input to drive KCs. Sparse coding in the temporal domain in cKCs can also result from selfinhibition due to spike-frequency adaptation as proposed for $\mathrm{cKCs}$ in honeybees based on the finding that systemic blocking of GABAergic transmission did not affect the temporal sharpness of KCs' ON responses (Farkhooi et al. 2013).

Concentration coding and gain control in Kenyon cells

In honeybees, population sparseness has been found in KCs' responses to different odorants (Szyszka et al. 2005), but concentration coding in KCs has not been studied yet. Here, we asked whether the $\mathrm{cKC}$ population code remains sparse when the odorant concentrations are increased. This was not the case for any of the odorants tested (Fig. 2). KC responses were concentration dependent over a wide range of odorant concentrations. Increasing odorant concentration increased the number of responding cKCs (Fig. 1d) and increased the response strength in the neuropil (Fig. 2a). In the neuropil the dendrites of adjacent cKCs overlap. Therefore, the positive concentration dependence of the neuropil response may reflect an increase in the number of responding $\mathrm{KCs}$ or an increase in the response strength of individual $\mathrm{KCs}$, or a combination of both. Taken together, our results show that honeybees' KCs are concentration dependent over a wide range of concentrations, and in this they are similar to their presynaptic neurons, the projection neurons in the honeybee antennal lobe (Sachse and Galizia 2003; Strauch et al. 2012). Our results contradict previous studies on concentration coding in $\mathrm{KCs}$, which found concentration-invariant population responses in locust and Drosophila (Stopfer et al. 2003; Honegger et al. 2011). However, our finding that $\mathrm{GABA}_{\mathrm{A}}$ and $\mathrm{GABA}_{\mathrm{B}}$ receptor-mediated inhibition reduces the degree of concentration dependence might indicate that GABA-mediated inhibition serves as a gain control which maintains some degree of KCs' sparseness even at high odorant concentrations. Similar conclusions were reached for the olfactory system of the locust (Stopfer 2005; Assisi et al. 2007). Such gain control ensures moderately 
increasing neuronal responses over a wide range of increasing odorant concentrations (Olsen and Wilson 2008; Sachse and Galizia 2002; Silbering and Galizia 2007; Yamagata et al. 2009).

\section{$\mathrm{ON}$ and OFF response dynamics in Kenyon cells}

The amplitude of cKCs' ON responses increased with increasing odorant concentration; however, their phasic time course hardly changed (Fig. 2a). This suggests that the number of odorant-evoked action potentials increases with increasing odorant concentration, while the generation of action potentials is restricted to a narrow time window during odorant onset. The absence of an effect of $\mathrm{GABA}_{\mathrm{A}^{-}}$ blockade at low odorant concentration indicates that $\mathrm{KCs}$ respond to low odorant concentrations with one or a few spikes at odorant onset, so that the delayed GABA input (delayed as compared to projection neurons input) is ineffective. The observation that the ON response amplitude did not differ between $100 \mathrm{~ms}$ and $3 \mathrm{~s}$ long odorant stimuli (Fig. 5a) suggests that cKCs' integration time window for projection neuron input is as short as $100 \mathrm{~ms}$.

The observation that $\mathrm{GABA}_{\mathrm{A}}$ receptor blockade increased the amplitude of $\mathrm{ON}$ responses, but did not change the phasic time course suggests that cKCs phasic response dynamic reflects an intrinsic property of the $\mathrm{cKC}$, such as spike-frequency adaptation (Farkhooi et al. 2013) rather than odorant-driven inhibitory input as suggested previously (Szyszka et al. 2005).

OFF responses are a dominant feature of cKC odorant responses (Szyszka et al. 2005, 2008) (Fig. 1). OFF responses increased with odorant concentration, as is the case for $\mathrm{ON}$ responses, and they increased with stimulus length as is the case in moth KCs (Ito et al. 2008). Although projection neurons respond to odorant pulses with highly structured spike trains as seen in intracellular recordings (Sun et al. 1993; Abel et al. 2001; Müller et al. 2002), OFF responses are rare and also rarely seen in $\mathrm{Ca}^{2+}$ imaging of projection neurons within the glomeruli of the AL (Sachse and Galizia 2003). Also, presynaptic boutons of projection neurons in the lip region of the MB calyx rarely show OFF responses (Szyszka et al. 2005; Yamagata et al. 2009), indicating that the sources of cKCs OFF responses lie postsynaptic to projection neuron output.

What is the physiological mechanism of cKCs' OFF responses? OFF responses are often generated by postinhibitory rebound activity due to increased excitability after a release from inhibition. If cKCs' OFF responses would reflect post-inhibitory rebound activity, they should disappear during GABA receptor blockade. However, we found no change in OFF responses during $\mathrm{GABA}_{\mathrm{A}}$ or $\mathrm{GABA}_{\mathrm{B}}$ receptor blockade. Therefore, we conclude that cKCs' OFF responses do not reflect GABA-mediated post- inhibitory rebound activity. Instead, cKCs OFF responses might reflect post-inhibitory rebound activity mediated by other inhibitory transmitters, such as histamine (Sachse et al. 2006), or they might be generated by intrinsic properties of $\mathrm{cKCs}$.

While the response dynamics and the modulation by GABAergic transmission were similar between cKCs in the lateral and median calyces, higher concentrated odorants evoked stronger ON responses in lateral calyces. A possible explanation for this difference could be an uneven innervation by projection neurons as shown by (Abel et al. 2001) on the basis of intracellularly stained projection neurons, or different inhibitory input via PCT neurons.

The role of GABA receptor transmission in the olfactory pathway

GABA acts as an inhibitory neurotransmitter in the olfactory circuit of the honeybee as documented by patch recordings of somatic currents in cultured neurons (Schäfer et al. 1994; Grünewald and Wersing 2008; Barbara et al. 2005) and by pharmacological experiments (El Hassani et al. 2008). The glomeruli of the antennal lobe in the honeybee are interconnected via a dense network of local interneurons (Schäfer and Bicker 1986; Sachse and Galizia 2002; Fonta et al. 1993; Krofczik et al. 2009), as is the case in other insect species, e.g., Drosophila (Wilson and Laurent 2005). These interneurons are mainly inhibitory and GABAergic. Less is known about the function of GABArelated inhibitory networks at the input to the $\mathrm{MB}$, the calyx. GABA-ir has been attributed to PCT neurons both with the light and electron microscope (Bicker et al. 1985; Ganeshina and Menzel 2001), and inhibitory $\mathrm{Ca}^{2+}$ responses have been measured in the presynaptic terminals of projection neurons in the lip region of the MB calyx (Yamagata et al. 2009); however, it is not known by which types of GABA receptors inhibition is mediated. We applied a pharmacological approach to elucidate the effect of blocking different GABA receptor types on response modulation in cKC. Since the GABA receptor blockers were applied to the whole brain, it is possible that the GABA receptor blocker-mediated increase of $\mathrm{cKC} \mathrm{ON}$ responses which we found here not only originates in the calyx of the MB, but also in upstream inhibitory networks, such as in the antennal lobe. Application of the $\mathrm{GABA}_{\mathrm{A}}$ receptor blocker PTX to the honeybee antennal lobe increases the odorant response amplitudes in projection neurons and the number of activated projection neurons (Sachse and Galizia 2002), and this increased projection neuron response could also lead to stronger input to $\mathrm{cKCs}$ within the MB lip. However, when using different $\mathrm{GABA}_{\mathrm{A}}$ receptor blockers, namely PTX and BMI, we obtained different results. While PTX increased the cKC response 
amplitude, BMI did not (Fig. 3b d). This is consistent with findings in Manduca projection neurons where BMI altered the temporal response patterns, but not the response magnitude (Lei et al. 2009).

To investigate the role of GABAergic transmission on the temporal resolution of $\mathrm{cKCs}$, we tested the effect of $\mathrm{GABA}_{\mathrm{A}}$ receptor blockade on quickly succeeding odorant pulses. Two short odorant pulses $(333 \mathrm{~ms})$ at an interval of $0.5 \mathrm{~s}$ induced paired-pulse depression (Fig. 5c). The decreased response to the second odorant pulse could reflect delayed GABAergic transmission from PCT neurons onto cKCs. $\mathrm{GABA}_{\mathrm{A}}$ receptor blockade increased the responses to both odorant pulses; however, the response to the second pulse was still smaller and the ratio of first to second response did not change. Thus, paired-pulse depression is not mediated by delayed inhibition via $\mathrm{GABA}_{\mathrm{A}}$ receptors and $\mathrm{GABA}_{\mathrm{A}}$ receptor-mediated inhibition does not affect the temporal resolution of cKCs. This result supports the hypothesis that there are at least three mechanisms which account for cKCs response properties: odorant-driven GABAergic input which attenuates ON responses, spike-frequency adaptation intrinsic to cKCs, which keeps ON responses short (Farkhooi et al. 2013), and a GABA-independent mechanism, which generates OFF responses after the termination of longer odorant stimulation.

In conclusion, our data suggest that $\mathrm{cKCs}$ are tuned to encode changes in odorant concentration at high temporal resolution rather than encoding the presence of a steadystate odorant stimulus. GABAergic inhibition could act as a gain control mechanism, which expands the dynamic range of cKCs' odorant responses, allowing them to encode a wide range of odorant concentrations without compromising the sparseness of the $\mathrm{cKC}$ population code.

Acknowledgments We are grateful to Drs. Silke Sachse, Melanie Haehnel and Nobuhiro Yamagata for their help and advice during the experiments. The work was supported by a grant of the Deutsche Forschungsgemeinschaft (Me 365/31 1).

\section{References}

Abel R, Rybak J, Menzel R (2001) Structure and response patterns of olfactory interneurons in the honeybee, Apis mellifera. J Comp Neurol 437:363 383

Asay MJ, Boyd SK (2006) Characterization of the binding of [3H]CGP54626 to GABAB receptors in the male bullfrog (Rana catesbeiana). Brain Res 1094:76 85

Assisi C, Stopfer M, Laurent G, Bazhenov M (2007) Adaptive regulation of sparseness by feedforward inhibition. Nat Neurosci 10:1176 1184

Barbara GS, Zube C, Rybak J, Gauthier M, Grünewald B (2005) Acetylcholine, GABA and glutamate induce ionic currents in cultured antennal lobe neurons of the honeybee, Apis mellifera. J Comp Physiol A 191:823 836
Bicker G (1999) Histochemistry of classical neurotransmitters in antennal lobes and mushroom bodies of the honeybee. Microsc Res Techniq 45:174 183

Bicker G, Schäfer S, Kingan TG (1985) Mushroom body feedback interneurones in the honeybee show GABA like immunoreac tivity. Brain Res 360:394 397

Chou YH, Spletter ML, Yaksi E, Leong JC, Wilson RI, Luo L (2010) Diversity and wiring variability of olfactory local interneurons in the Drosophila antennal lobe. Nat Neurosci 13:439 449

Choudhary AF, Laycock I, Wright GA (2012) gamma Aminobutyric acid receptor A mediated inhibition in the honeybee's antennal lobe is necessary for the formation of configural olfactory percepts. Eur J Neurosci 35:1718 1724

Davis RL (1993) Mushroom bodies and Drosophila learning. Neuron 11:1 14

Deglise P, Grünewald B, Gauthier M (2002) The insecticide imidacloprid is a partial agonist of the nicotinic receptor of honeybee Kenyon cells. Neurosci Let 321:13 16

Demmer H, Kloppenburg P (2009) Intrinsic membrane properties and inhibitory synaptic input of Kenyon cells as mechanisms for sparse coding? J Neurophysiol 102:1538 1550

El Hassani AK, Giurfa M, Gauthier M, Armengaud C (2008) Inhibitory neurotransmission and olfactory memory in honey bees. Neurobiol Learn Mem 90:589 595

Enell L, Hamasaka Y, Kolodziejczyk A, Nässel DR (2007) gamma Aminobutyric acid (GABA) signaling components in Drosoph ila: immunocytochemical localization of $\mathrm{GABA}(\mathrm{B})$ receptors in relation to the $\mathrm{GABA}(\mathrm{A})$ receptor subunit $\mathrm{RDL}$ and a vesicular GABA transporter. J Comp Neurol 505:18 31

Farkhooi F, Froese A, Muller E, Menzel R, Nawrot MP (2013) Cellular adaptation facilitates sparse and reliable coding in sensory pathways. PLoS Comput Biol 9(10):e1003251

Fonta C, Sun XJ, Masson C (1993) Morphology and spatial distribution of bee antennal lobe interneurons responsive to odors. Chem Sens 18:101 119

Galizia CG, Kimmerle B (2004) Physiological and morphological characterization of honeybee olfactory neurons combining electrophysiology, calcium imaging and confocal microscopy. J Comp Physiol A 190:21 38

Galizia CG, Joerges J, Kuttner A, Faber T, Menzel R (1997) A semi in vivo preparation for optical recording of the insect brain. J Neurosci Method 76:61 69

Ganeshina O, Menzel R (2001) GABA immunoreactive neurons in the mushroom bodies of the honeybee: an electron microscopic study. J Comp Neurol 437:335 349

Grünewald B (1999a) Morphology of feedback neurons in the mushroom body of the honeybee, Apis mellifera. J Comp Neurol 404:114 126

Grünewald B (1999b) Physiological properties and response modu lations of mushroom body feedback neurons during olfactory learning in the honeybee Apis mellifera. J Comp Physiol A 185(6):565 576

Grünewald B, Wersing A (2008) An ionotropic GABA receptor in cultured mushroom body Kenyon cells of the honeybee and its modulation by intracellular calcium. J Comp Physiol A 194:329 340

Haehnel M, Menzel R (2010) Sensory representation and learning related plasticity in mushroom body extrinsic feedback neurons of the protocerebral tract. Front Syst Neurosci 4:161

Haehnel M, Menzel R (2012) Long term memory and response generalization in mushroom body extrinsic neurons in the honeybee Apis mellifera. J Exp Biol 215:559 565

Heisenberg M (2003) Mushroom body memoir: from maps to models. Nat Rev Neurosci 4:266 275

Honegger KS, Campbell RAA, Turner GC (2011) Cellular resolution population imaging reveals robust sparse coding in the Dro sophila mushroom body. J Neurosci 31:11772 11785 
Huang J, Zhang W, Qiao W, Hu A, Wang Z (2010) Functional connectivity and selective odor responses of excitatory local interneurons in Drosophila antennal lobe. Neuron 67:1021 1033

Ito I, Ong RCY, Raman B, Stopfer M (2008) Sparse odor representation and olfactory learning. Nat Neurosci 11:1177 1184

Jortner RA, Farivar SS, Laurent G (2007) A simple connectivity scheme for sparse coding in an olfactory system. J Neurosci 27:1659 1669

Krofczik S, Menzel R, Nawrot MP (2009) Rapid odor processing in the honeybee antennal lobe network. Front Comput Neurosc 2:9

Laurent G (2002) Olfactory network dynamics and the coding of multidimensional signals. Nat Rev Neurosci 3:884 895

Laurent G, Stopfer M, Friedrich RW, Rabinovich MI, Volkovskii A, Abarbanel HDI (2001) Odor encoding as an active, dynamical process: experiments, computation, and theory. Annu Rev Neurosci 24:263 297

Lei H, Riffell JA, Gage SL, Hildebrand JG (2009) Contrast enhancement of stimulus intermittency in a primary olfactory network and its behavioral significance. J Biol 8:21

Lei Z, Chen K, Li H, Liu H, Guo A (2013) The GABA system regulates the sparse coding of odors in the mushroom bodies of Drosophila. Biochem Biophys Res Comm 436:35 40

Leitch B, Laurent G (1996) GABAergic synapses in the antennal lobe and mushroom body of the locust olfactory system. J Comp Neurol 372:487 514

Menzel R (2012) The honeybee as a model for understanding the basis of cognition. Nat Rev Neurosci 13:758 768

Mobbs PG (1982) The brain of the honeybee Apis mellifera.1. The connections and spatial organization of the mushroom bodies. Philos T Roy Soc B 298:309 354

Müller D, Abel R, Brandt R, Zockler M, Menzel R (2002) Differential parallel processing of olfactory information in the honeybee, Apis mellifera L. J Comp Physiol A 188:359 370

Murthy M, Fiete I, Laurent G (2008) Testing odor response stereotypy in the Drosophila mushroom body. Neuron 59:1009 1023

Olsen SR, Wilson RI (2008) Lateral presynaptic inhibition mediates gain control in an olfactory circuit. Nature 452:956 960

Papadopoulou M, Cassenaer S, Nowotny T, Laurent G (2011) Normalization for sparse encoding of odors by a wide field interneuron. Science 332:721 725

Pelz C, Gerber B, Menzel R (1997) Odorant intensity as a determinant for olfactory conditioning in honeybees: roles in discrimination, overshadowing and memory consolidation. J Exp Biol 200:837 847

Perez Orive J, Mazor O, Turner GC, Cassenaer S, Wilson RI, Laurent G (2002) Oscillations and sparsening of odor representations in the mushroom body. Science 297:359 365

Perez Orive J, Bazhenov M, Laurent G (2004) Intrinsic and circuit properties favor coincidence detection for decoding oscillatory input. J Neurosci 24:6037 6047

Root CM, Masuyama K, Green DS, Enell LE, Nassel DR, Lee CH, Wang JW (2008) A presynaptic gain control mechanism fine tunes olfactory behavior. Neuron 59:311 321

Rotte C, Witte J, Blenau W, Baumann O, Walz B (2009) Source, topography and excitatory effects of GABAergic innervation in cockroach salivary glands. J Exp Biol 212:126 136

Rybak J, Menzel R (1993) Anatomy of the mushroom bodies in the honey bee brain: the neuronal connections of the alpha lobe. J Comp Neurol 334:444 465

Sachse S, Galizia CG (2002) Role of inhibition for temporal and spatial odor representation in olfactory output neurons: a calcium imaging study. J Neurophysiol 87:1106 1117
Sachse S, Galizia CG (2003) The coding of odour intensity in the honeybee antennal lobe: local computation optimizes odour representation. Eur J Neurosci 18:2119 2132

Sachse S, Peele P, Silbering AF, Gühmann M, Galizia CG (2006) Role of histamine as a putative inhibitory transmitter in the honeybee antennal lobe. Front Zool 3:22

Schäfer S, Bicker G (1986) Distribution of GABA like immunore activity in the brain of the honeybee. J Comp Neurol 246:287 300

Schäfer S, Rosenboom H, Menzel R (1994) Ionic currents of Kenyon cells from the mushroom body of the honeybee. J Neurosci 14:4600 4612

Seki Y, Rybak J, Wicher D, Sachse S, Hansson BS (2010) Physiological and morphological characterization of local inter neurons in the Drosophila antennal lobe. J Neurophysiol 104:1007 1019

Silbering AF, Galizia CG (2007) Processing of odor mixtures in the Drosophila antennal lobe reveals both global inhibition and glomerulus specific interactions. J Neurosci 27:11966 11977

Stopfer M (2005) Olfactory coding: inhibition reshapes odor responses. Curr Biol 15:R996 R998

Stopfer M, Bhagavan S, Smith BH, Laurent G (1997) Impaired odour discrimination on desynchronization of odour encoding neural assemblies. Nature 390:70 74

Stopfer M, Jayaraman V, Laurent G (2003) Intensity versus identity coding in an olfactory system. Neuron 39:991 1004

Strauch M, Ditzen M, Galizia CG (2012) Keeping their distance? Odor response patterns along the concentration range. Front Syst Neurosci 6:71

Strausfeld NJ (2002) Organization of the honey bee mushroom body: representation of the calyx within the vertical and gamma lobes. J Comp Neurol 450:4 33

Sun XJ, Fonta C, Masson C (1993) Odor quality processing by bee antennal lobe interneurons. Chem Sens 18:355 377

Szyszka P, Ditzen M, Galkin A, Galizia CG, Menzel R (2005) Sparsening and temporal sharpening of olfactory representations in the honeybee mushroom bodies. $\mathrm{J}$ Neurophysiol 94:3303 3313

Szyszka P, Galkin A, Menzel R (2008) Associative and non associative plasticity in Kenyon cells of the honeybee mushroom body. Front Syst Neurosci 2:3

Turner GC, Bazhenov M, Laurent G (2008) Olfactory representations by Drosophila mushroom body neurons. J Neurophysiol 99:734 746

Wang Y, Guo HF, Pologruto TA, Hannan F, Hakker I, Svoboda K, Zhong Y (2004) Stereotyped odor evoked activity in the mushroom body of Drosophila revealed by green fluorescent protein based $\mathrm{Ca} 2$ + imaging. J Neurosci 24:6507 6514

Wilson RI, Laurent G (2005) Role of GABAergic inhibition in shaping odor evoked spatiotemporal patterns in the Drosophila antennal lobe. J Neurosci 25:9069 9079

Wright GA, Carlton M, Smith BH (2009) A honeybee's ability to learn, recognize, and discriminate odors depends upon odor sampling time and concentration. Behav Neurosci 123:36 43

Yamagata N, Schmuker M, Szyszka P, Mizunami M, Menzel R (2009) Differential odor processing in two olfactory pathways in the honeybee. Front Syst Neurosci 3:16

Yarali A, Ehser S, Hapil FZ, Huang J, Gerber B (2009) Odour intensity learning in fruit flies. P Roy Soc B 276:3413 3420 